\title{
Research on the Danger Liability of Space Launch's Damage to the Third Party
}

\author{
Li Yajuan \\ Department of law Northwestern Polytechnical University Shaanxi Province China \\ lyajoan@163.com
}

\begin{abstract}
The space launch activities might cause harm by the falling of relevant spare parts or debris of spacecraft to the personal, property rights or interests of the third party in China's territorial land, territorial seas and territorial airspace. This act of tort should fall into civil tort, in which the damaged third party is the victim, while all the sides participating in space launch are the responsible persons. The damage caused by the space launch activities should be applicable to greatly hazardous liability. As to the liability principle, it should be strict liablity.
\end{abstract}

Key words: space launch, the third party, damage, hazardous liability

Tort Liability Law of the People's Republic of China conducted from July 1st, 2010 stipulates high-risk liability, defining that the managers should bear liability for tort for the damage done by high altitude operation, high pressure activities, mine working or high-speed rail transportation. With the rapid development of aerospace industry, the behavior of damage to the third party by the space launch activities becomes increasingly frequent; however, there are hardly any cases of the claim for compensation by the damaged third party through the institutionalized approaches. This issue should be the research content of tort liability law.

\section{The Posing of Problem}

Since the 1950s, the human's exploration of outer space has been constantly deepening. With the flourishing development of outer space activities, it also brings about various damage liability problems such as the spacecraft accidents, space debris and so on, which have become the problems to be settled. The damage to the third party caused by the space launch activities in our country is also an unavoidable problem. When rocket booster and one-stage rocket are throwned away after finishing their work, the wreckage will generally fall into the place within 1000 kilometres east of the firing point. In addition, with the risks of space launch itself and the possibilities of failures in launch, consequently, the damage to the third party is almost hard to avoid. The damage includes direct personal damage and property damage; the damage to human body, atmosphere and the surroundings caused by the poisonous air emitted from the wreckage; the mental panic among the people in the falling area of wreckage, etc.

Presently, there have been more than 100 times of space launch, carried out in three launching sites, i.e., Jiuquan, Taiyuan and Xichang, which include sending no less than 100 satellites and spaceships for seven times into space. The theoretical falling areas of wreckage in these three launching sites are mainly divided into four regions as follows: Firstly, County of Suichuan in Jiangxi had been set by the relevant departments to be the prospective falling region of satellite wreckage before the year of 2000. They mainly consist of the town of Gaoping, Tanghu, Zuoan, Heyuan and the country of Nanjiang. Secondly, county of Suining, Shaoyang in Hunan had succeeded for 15 times in recycling one-stage wreckage of satellite launch vehicle by Xichang Satellite Launching Center by the time of 2009. Thirdly, town of Jiuchang, Renhuai in Guizhou is an old falling region of our satellite launch. In the preceeding two decades, the commander department of falling region in Guizhou has finished the recycling tasks for more than ten times, covering 19 counties (cities) of 7 cities (states,areas), with nearly two million citizens and an area of more than 4000 square kilometers. At last, the theoretical center of falling region in Tianlin,Guangxi is located in Pingzuotun,Boe Village of Baduyaozu. But for the remote geographical position and many mountain forests,the county of Tianlin has become an ideal falling area of rocket wreckage ${ }^{[1]}$.

As to the whole Guizhou Province, the history about falling rocket from the sky has lasted for more than 30 years. On Nov $26^{\text {th }}$, 1975, the wreckage of the first retrievable satellite launched by LM-2F rocket for the first time in China fell in Yingpan, Guizhou three days later. In 1995, the rocket wreckage cut off the nose of farm cattle, while falling in Guwang, Fuquan, Guizhou. In July, 1996, LM-3F rocket launched a communication satellite called APSTAR 1A. Its one-stage rocket wreckage fell in Wengjiao Village at the border of Wengan and Yuqing in Guizhou, with some civilian houses being shaken apart. On Oct $24^{\text {th }}, 2007$, LM-3A launch vehicle carried Chang'E-1 lunar satellite to outer space. Its wreckage fell in a corn field of Apple Group in Daoping, Fuquan $^{[2]}$. Space launch's damage to the third party exists in the objective reality; however, there are still no institutionalized solutions. Some news reports once revealed the situations of conpensation for space launch's damage to the third party ${ }^{[3]}$. "According to the inform previously issued, the government would make compensation for the financial damage caused by rocket falling." At 00:20 p.m. on May 27th, 2012, Armed Police Force of Suining County successively recieved the phone from the directors of Armed Force of Wawutang Township and Shuikou Township, finding that the

*This paper is outcome of humanities funds of Northwestern Polytechnical University, RW201012. 
one-stage wreckage of LM-3B launch vehicle broke a civilian house as well as a 10,000V high-voltage line. Armed Police Force of Suining County subsequently demanded for protecting the spot, waiting until daybreak to make a specific registration and then compensate for it according to National Compensation Law ${ }^{[4]}$.

At the initial stage of space launch activities, the activities were all carried out by government. However, as the competition in exploration and development of outer space in many of the countries becomes more and more fierce, the space technology is continuously advancing, and consequently, the relevant business market is arising gradually. Up to present, the space launch industry has developed to be a very important and relatively mature one among space industries. As referred in Research on the world market of satellite construction and launch before 2019 newly issued by European consulting firm, in the next decade, the revenue from the construction and launch of 1220 satellites by relevant companies in the world would reach $\$ 194$ billion $^{[5]}$. On one hand, the space launch market is tending to commercialized operation. On the other hand, the innocent damaged third party in the falling area can only get unbalanced compensation far too often. Moreover, the commercialized operation of space industry makes state compensation liability to no longer conform to the present legal provisions. Therefore, the paper attempts to analyse the compensation for space launch's damage to the third party from the perspective of liability principle, and to definitude the compensation liability system of space launch's damage to the third party.

\section{The definition of third party's claim for compensation in the space launch}

The third party damage compensation in the space launch involves the harm behavior, the third party, and the definition of damage, so it is necessary to define.

According to the United Nations the "International Convention on the liability for damage caused by space objects" In 1972 "Space launch may cause damage to the people on the ground and the third aircraft, and other countries space objects or the persons who stays inside of the space object." It can be confirmed from this provision. Because of the different damage location, it can be divided into the third party on the ground (the ground here refers to the range of earth's gravity) and the third party in outer space. The third party on ground included of the third party in emission country and third party in overseas. No matter space launch activities carry on the surface of the earth or in the outer space, it caused the third party in overseas who suffers a loss. It will produce the international responsibilities, and relates to the field of international laws. The claim should be based on the principle and rules from the international space law to solve the problem, this paper will not cover it.

In China, the Xichang satellite launch center, the first satellite launch rocket debris falling area in southeast of Guizhou Province, followed by the southwest of Hunan Province. After throwing away the rocket boosters and the rockets arrows body, the debris will generally fall within 1000 kilometres east of the launching point. There are three big launch centers-Xichang launch center, Jiuquan launch center, and Taiyuan launch center. And the Xichang launch center's and Taiyuan launch center's launch spacecraft debris are likely to fall in the densely populated areas. The damage to the third party may be produced. At present, all the data shows that the dropping areas are in China, and the damage was confined within the territory of China. This paper discusses the damage caused by the space launch refers to the space launch activities involved the spacecraft components, fragments or debris or failure to launch the spacecraft crashed in the Chinese territory, territorial waters, airspace scope within the territory of China, leading to the damage for the third party or property . The third party and property in this paper are relative to the parties who are participates in the activity of the space launch. The reason why it called the third party is that the third person in the water or on the ground has nothing to do with the activities of the space launch or any contractual relationship with. When the third party suffered damage, there are not any contract terms can be adduced to investigate the operator or all contractual obligations. With reference to our country civil aviation law, tort liability for third parties on the surface or in the water, it defines the meaning of water, third parties on the surface-- "refers to a person having nothing to do with air transport aircraft operator, directly or indirectly participate in any activities, damaged by the aircraft accident run by the operator ${ }^{[6]}$. The third party in this paper who involved in the damage because of the activities of the space launch, with the aircraft operator or launch space launch activities engaged in by people who have nothing to do, not directly or indirectly involved in any activity space, but because of the space launch activities damage the third party in China. Because of space launch activity caused the damage to a third party. Those objects are space launch spacecraft debris or the failure of the spacecraft perform hierarchical fall off during drop boosters remains on the surface of the earth, parts or pieces, fairing, etc

\section{Liability principle of third party's claim for compensation in the space launch}

Liability principle, working after an actor's behaviors bring damages to others, is used to define who should be liable for damages. Until now, there is no uniform formulation on liability principle of third party's claim for compensation in the space launch. According to section 2 in "Convention on The Liability” in 1972, the launching state is absolutely liable for compensation if its space objects damage the surface of the earth or aircrafts in flight. That is actually to say, once the launching behavior brings about damages to the third party on the ground, the international law takes the state as the subject of liability and absolute liability as the principle of imputation. Although in section 7, the appliance of this convention in case of people in launching country as victim is excluded ${ }^{[7]}$, the confirmed principle of imputation remains an example. 
When the launching behavior causes damages to the third person in launching country, the applicable law will be the launching state's domestic law. So far, there is no clear legal provision involving in this kind of damage. Rather, for a long time, the launch behavior has been regarded as national act, and what the launch behavior damages is seen as national liability. In the falling area, the local government and people look upon the damages causing by the launch behavior as their contribution to national space undertaking. As a result, in most cases the compensation cannot embody the principle of indemnity as a token. As mentioned previously, more and more launch behaviors involve business interest. Although some launch behaviors belong to governmental act or military act, the subject of the launch is a separate legal entity who is capable of bearing civil liability independently. Therefore the view that the state is liable for damages causing by the launch behavior to a third party should be wiped out. For the third party subjecting damages, it is reasonable to define the injuring party, liability principle, extent of damage and even regime of liability. Abiding by Article 123 of China's "General Principles of The Civil Law", if any person causes damage to other people by engaging in operations that are greatly hazardous to the surroundings, such as operations conducted high aboveground, or those involving high pressure, high voltage, combustibles, explosives, highly toxic or radioactive substances or high-speed means of transport, he shall bear civil liability; however, if it can be proven that the damage was deliberately caused by the victim, he shall not bear civil liability. Abiding by Article 73 of "Tort Liability Law of the PRC”, where any harm is caused to another person by an aerial, high pressure or underground excavation activity or by the use of high speed rail transport vehicle, the operator shall assume the tort liability unless it can prove that the harm is caused by the victim intentionally or by force majeure. Compared to Article 157 of "Civil Aviation Law of the People's Republic of China", any person on the surface (including water surface, the same below) who suffers death or personal injury or damage to property caused by a civil aircraft in flight or by any person or thing falling therefore shall be entitled to compensation. We can understand from "General Principles of The Civil Law of the PRC", "Tort Liability Law of the PRC" and "Civil Aviation Law of the People's Republic of China" that non-fault attribution rule should adapt to tortuous act causing by high dangerous aboveground (including high aboveground).

The above provisions do not definitely bring the space launch activity into the scope of causing damages. However, the launch behavior is surely dangerous; it is likely to bring about damages if the launch fails ${ }^{[8]}$; the hierarchically falling parts have the risk of damaging people, land or other's movable property ${ }^{[9]}$; moreover, the spacecraft debris causing by the launch abort or booster debris, parts and pieces, and the fairing falling hierarchically in the process of launching are injuring materials for the water and the third person on the ground. So there is a causal relationship between the launch behavior and the damage.
As for the point whether the fault of the party engaging in the space launch is necessary, some researches suggest the launch activity has the characteristic of high danger and the victims do not have plenty knowledge and ability to judge and avoid the damage ${ }^{[10]}$. The author also agrees with this view. Moreover, it is difficult for the victim to prove the fault of the launch behavior. Therefore, from the point of fairness, it is not necessary to confirm the launch party's subjective fault if the launch behavior causes damages to the third party.

Therefore, in view of no special law in China at present, "General Principles of The Civil Law" and "Tort Liability Law" should adapt to the third party's claim for compensation in space launch, and the principle of faultless is applicable because of the greatly hazardous tort behavior.

China started late on aerospace legislation, and in many ways is still blank. Once the accident happens, there is no legislation for compensation. The rights of a third person suffered damage, and is very difficult to secure. In the rapid development of China's space technology and space industry. Due to the launch behavior and damage the third person's interests should also be reflected in the law. The lack of explicit damage compensation legal system is unfair to the third party, also against the development of aerospace industry. So we should clear space launch of the third party for compensation system in our country, in order to protect the interests of the damage to the third party. Right now, due to absence of the third party of damages law, we should handle this type of compensation for damages just justified by Principle of Civil Law and Tort Law, rather than by the state usual compensation. It belongs to greatly hazardous liability in compensation can apply the principle of no-fault imputation principles, and on the compensation liability subject to the organization of space launch and the organization of implementation.

\section{References}

[1] Above the fall areas according to the network data compilation.

[2] Yang Meng, the rocket is coming! Quickly hide! Southern Metropolis Weekly Vol7 2010.

[3] Yang Meng, the rocket is coming! Quickly hide! Southern Metropolis Weekly Vol7 2010.

[4] Long march rocket debris fall in Hunan province, homes and hightension line were broken , Yangzi evening news network [EB/OL]. http://www.yangtse.com/system/2012/05/28/013423172.shtml 28th May 2012.

[5] QinWei , "Space Economy” Age is coming Quietly , Fabrication \& Assembly Vol11 2010 Page51.

[6] HaoXiuhui. Aircraft on ground (water) face cause the damage for the third party's tort imputation principle theory . Northern Legal Science.Vol7 Book Two Page119.

[7] 《Convention on the international responsibility of the outer space objects caused by damage》 Amendment VII : Outside of the provisions of this convention shall not apply to launch the damage caused to the following persons of an empty object : ( a ) The launch of the national ; ( b ) foreign national, Launch from the outer space objects or any of the following stages until landing to the object within the period of operation, or at the invitation of the launch of the scheduled launch or recover the immediate region of the period. 
[8] [U.S.] Vincent• R・ Johnson Translation by Zhao Xiuwen American Tort Law .Beijing : China Renmin University Press Page196,2004.

[9] [U.S.] Vincent $\bullet$ R Johnson Translation by Zhao Xiuwen American Tort Law Beijing : China Renmin University Press Page196,2004.
[10] Compose by Yin Yuhai etc. The several legal issues research for spacecraft launch .Beijing : China Democracy and Law Press Page331 2008. 